Supplement of Biogeosciences, 13, 1933-1947, 2016

http://www.biogeosciences.net/13/1933/2016/

doi:10.5194/bg-13-1933-2016-supplement

(C) Author(s) 2016. CC Attribution 3.0 License.

(c) (1)

Supplement of

\title{
Carbon sequestration in managed temperate coniferous forests under climate change
}

Caren C. Dymond et al.

Correspondence to: Caren C. Dymond (caren.dymond@gov.bc.ca)

The copyright of individual parts of the supplement might differ from the CC-BY 3.0 licence. 
Supplementary to Dymond et al Pine Creek climate change modelling.
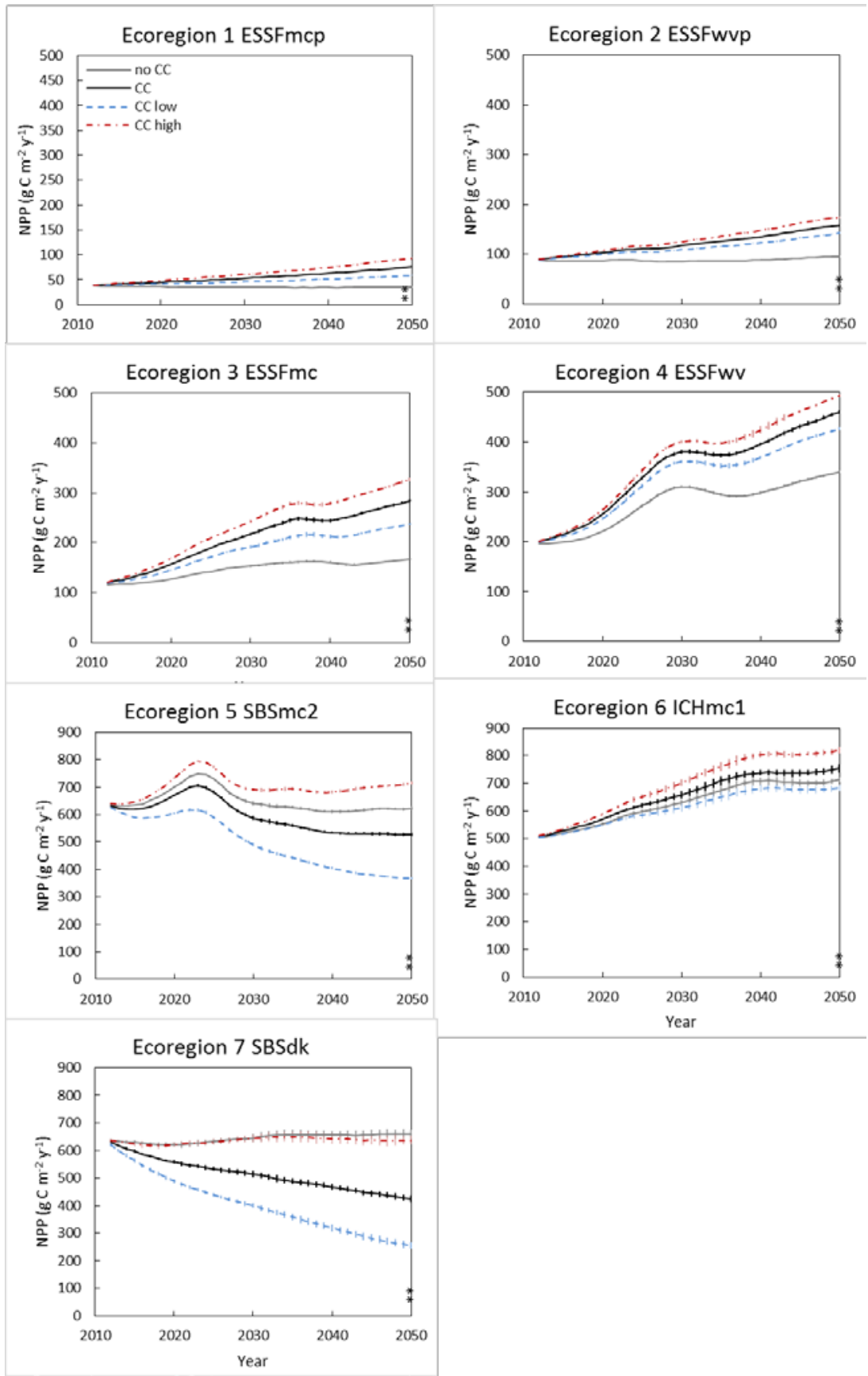

Figure S1 Climate change projections of the NPP (average \pm SD) rates for each ecoregion. Asterisk notes t-tests that were significantly different between the no change scenario and average productivity scenario $(* * P<0.01)$ in 2050 . Note, $y$ axes vary. 

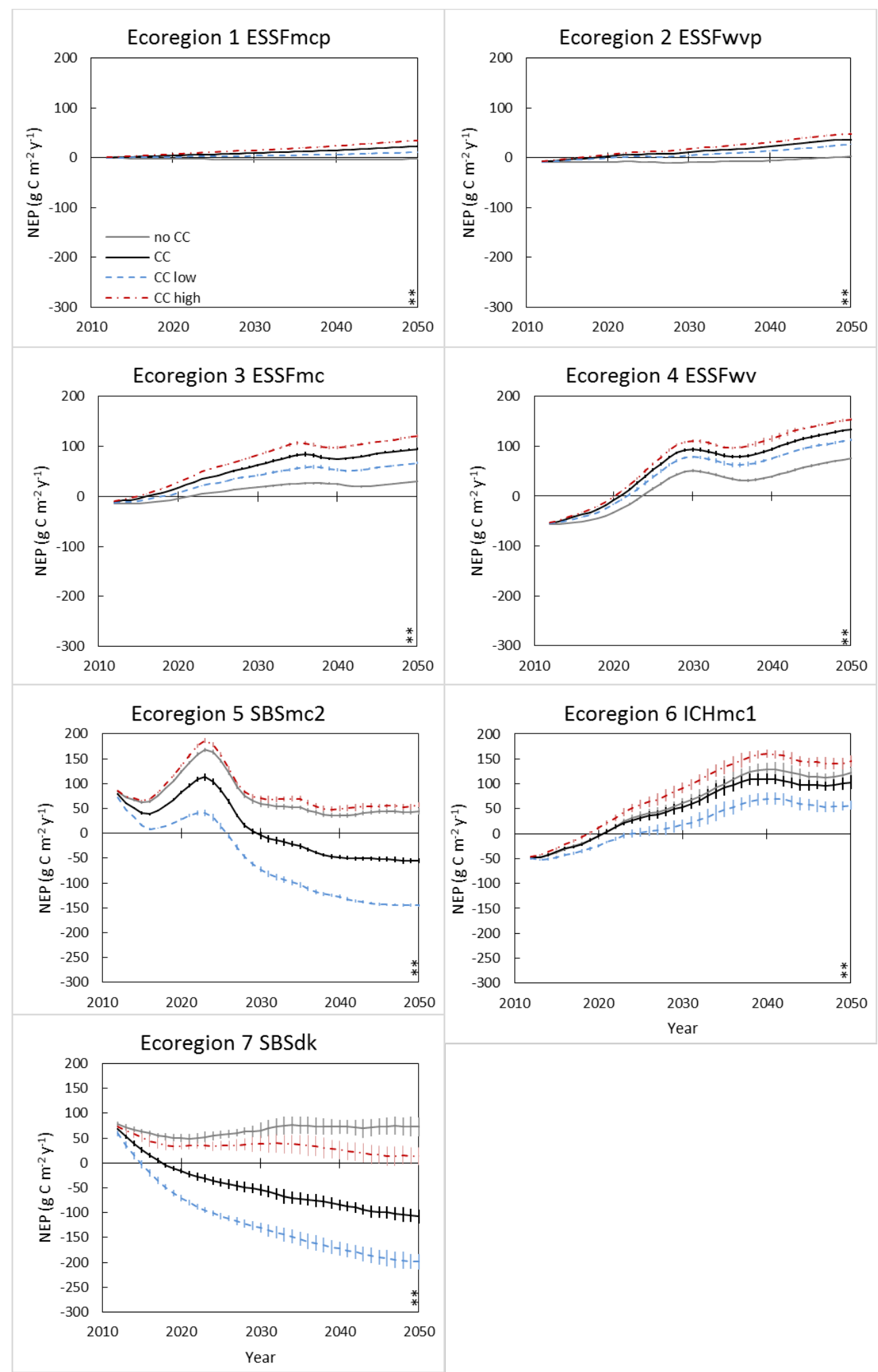

Figure 2 Climate change impact projections on the NEP (average \pm SD) rates for each ecoregion. Asterisk notes t-tests that were significantly different between the no change scenario and climate change average productivity $(* * \mathrm{P}<0.01)$ in 2050. Note, y-axes vary. 

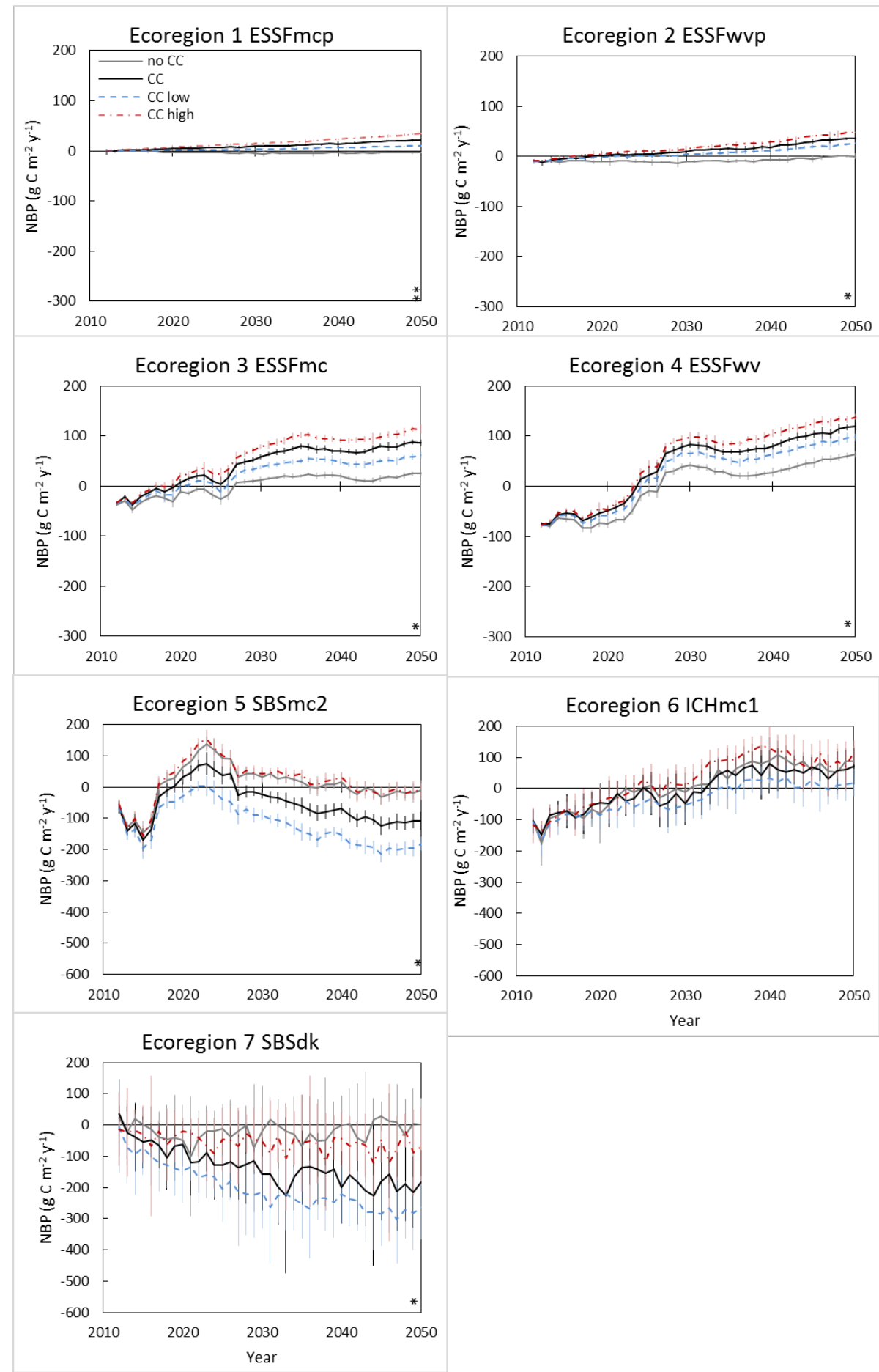

Figure 3 Climate change impact projections on the NBP (average \pm SD) rates for each ecoregion. Asterisk notes t-tests that were significantly different between the no change scenario and climate change average productivity $\left({ }^{* *} \mathrm{P}<0.01,{ }^{*}\right.$ $P<0.05)$ in 2050. Note, $y$-axes vary. 


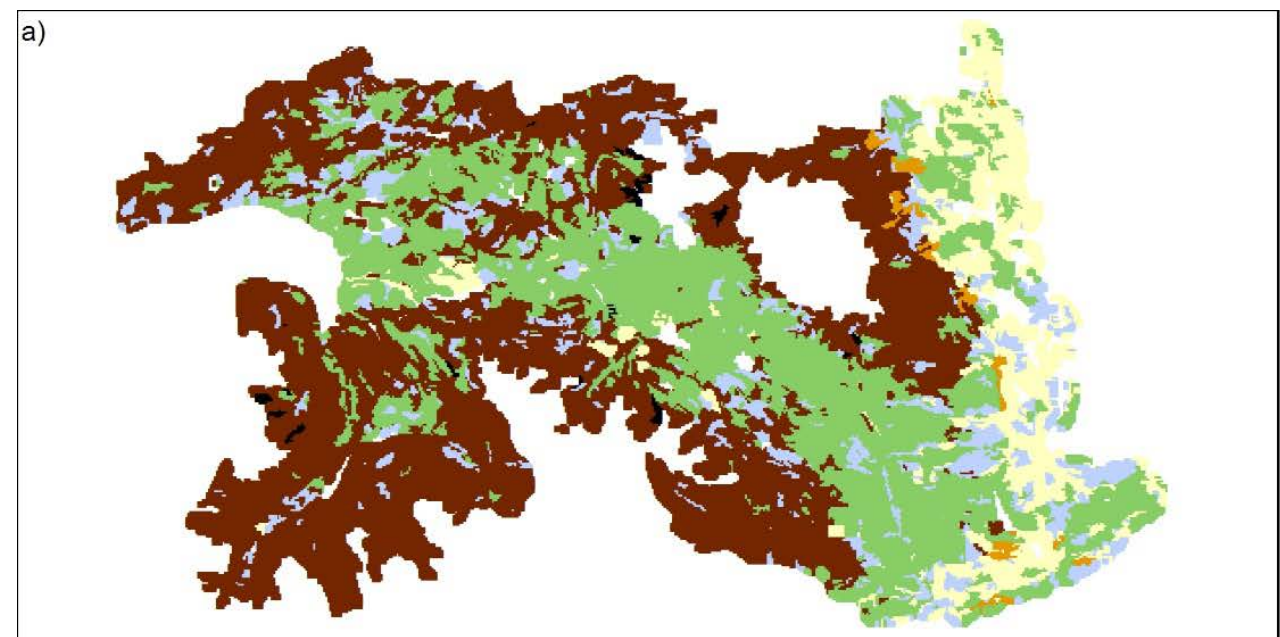

Starting conditions

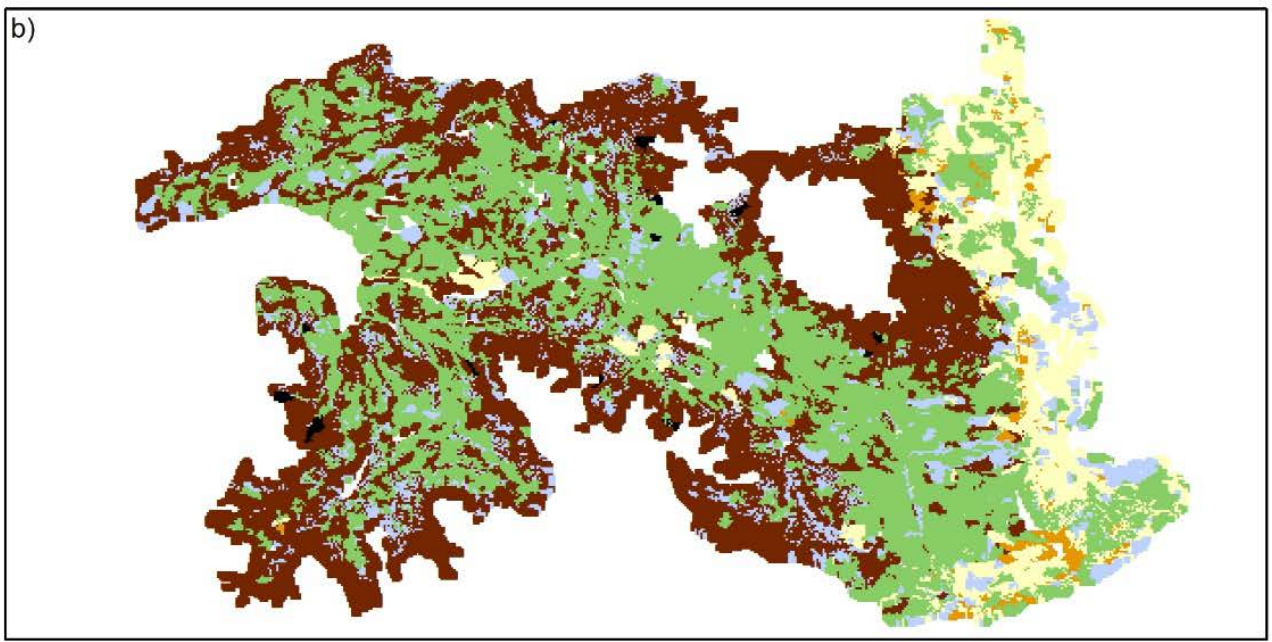

2050 climate change high

\section{Leading species}

- Ac or Ep

At

- BI

- $\mathrm{PI}$

- $\mathrm{Pa}, \mathrm{Sb}$, $\mathrm{Hw}$ or $\mathrm{Ba}$

Ex

$\square \quad$ Non-forest

Figure 4 Leading species distribution with starting conditions or in 2050 under the high productivity scenario. 